\title{
Bacterial meningitis and neurological complications in adults
}

\author{
Parunyou Julayanont MD, Doungporn Ruthirago MD, John C. DeToledo MD
}

\begin{abstract}
Bacterial meningitis is a leading cause of death from infectious disease worldwide. The neurological complications secondary to bacterial meningitis contribute to the high mortality rate and to disability among the survivors. Cerebrovascular complications, including infarction and hemorrhage, are common. Inflammation and increased pressure in the subarachnoid space result in cranial neuropathy. Seizures occur in either the acute or delayed phase after the infection and require early detection and treatment. Spreading of infection to other intracranial structures, including the subdural space, brain parenchyma, and ventricles, increases morbidity and mortality in survivors. Infection can also spread to the spinal canal causing spinal cord abscess, epidural abscess, polyradiculitis, and spinal cord infarction secondary to vasculitis of the spinal artery. Hypothalamic-pituitary dysfunction is also an uncommon complication after bacterial meningitis. Damage to cerebral structures contributes to cognitive and neuropsychiatric problems. Being aware of these complications leads to early detection and treatment and improves mortality and outcomes in patients with bacterial meningitis.
\end{abstract}

Key words: meningitis; meningitis, bacterial; central nervous system bacterial infection; nervous system diseases

\section{INTRODUCTION}

Bacterial meningitis is a leading cause of death from infectious disease worldwide. Despite the availability of increasingly effective antibiotics and intensive neurological care, the overall mortality remains high, with $17-34 \%$ of the survivors having unfavorable outcomes. ${ }^{1,2,3}$ Neurological complications associated with bacterial meningitis are major contributing factors to this high disability and mortality among survivors. Being aware of these potential complications leads to early detection and treatment and may im-

Corresponding author: Parunyou Julayanont, MD Contact Information: p.julayanont@ttuhsc.edu DOI: 10.12746/swrccc 2016.0414.182 prove recovery and outcomes.

In this article, we present a case of bacterial meningitis complicated by an unusual number of neurological complications that occurred in spite of a timely diagnosis, adequate treatment, and intensive neurological monitoring. We also review various neurological complications of bacterial meningitis in adults with emphasis on the incidence, clinical characteristics, pathophysiology, and treatment.

\section{CASE}

A 45-year-old man with rheumatoid arthritis and chronic hepatitis $\mathrm{C}$ infection presented with a two day history of low grade fever and confusion and required intubation. He had been recently treated for sinusitis 
with five days of amoxicillin-clavulanate. Head computed tomography (CT) without contrast on admission showed the subarachnoid hemorrhage (SAH) in the fronto-parieto-temporal convexities and Sylvian fissures bilaterally. He also had opacification of the maxillary and sphenoid sinuses. Computed tomography angiography showed no aneurysm or any other explanation for the subarachnoid hemorrhage. A lumbar puncture showed yellowish cerebrospinal fluid (CSF) with 4,352 WBCs (neutrophils $87 \%$, lymphocytes $2 \%$, and monocytes $11 \%$ ) and 1,707 RBCs with positive xanthochromia. The opening pressure was $58 \mathrm{cmH}_{2} \mathrm{O}$, protein was $442 \mathrm{mg} / \mathrm{dL}$, and glucose was $3 \mathrm{mg} / \mathrm{dL}$. Cerebral spinal fluid gram stain and culture, S. pneumoniae, $H$. influenzae, N. meningitides antigen panel, cryptococcal antigen, beta D-glucan, fungal and mycobacterial cultures, and herpes simplex virus-1,2 DNA were all negative. The patient was empirically started on high dose ceftriaxone and vancomycin. Pus cultured from the left maxillary and ethmoid sinuses showed skin flora. Magnetic resonance imaging (MRI) of the head with gadolinium showed scattered leptomeningeal enhancement with residual $\mathrm{SAH}$. His level of consciousness markedly improved, and he was extubated after seven days of antibiotics.

One week after extubation, the patient had an acute change in mental status. A repeat MRI showed hydrocephalus, obstruction of the cerebral aqueduct, and intraventricular empyema of the occipital horns of the lateral ventricles. It also showed a subdural empyema in the posterior fossa. He underwent posterior craniotomy with right occipital ventriculostomy. Intraoperatively, large amounts of pus were drained from the posterior fossa. No organisms grew from this culture. He had an MRI of the whole spine performed due to persistent leukocytosis and back pain. The MRI showed an epidural abscess extending from T9 to the thecal sac. Three milliliters of pus was aspirated from the epidural space between L1 and L2 level. No organism was found in the epidural pus.

A follow up head MRI showed new areas of ischemic infarction at right medial pons, left capsulothalamic area, right-sided splenium of corpus callosum, and mesial temporal areas bilaterally. A magnetic resonance angiogram of the head and neck showed diffuse irregularity of the intracranial arteries consistent with a diffuse intracranial vasculitis.

Over the next six weeks his condition improved significantly, and he was discharged to an inpatient rehabilitation facility with a modified Rankin Scale of 4. He could not remember events during his hospitalization. Three months later, he had some recovery with a modified Rankin Scale of 3 and a Barthel index of $55 / 100$.

\section{Discussion}

\section{Cerebrovascular complications}

Ischemic and hemorrhagic strokes are common complications of bacterial meningitis. These complications are reported in $14-37 \%$ of patients and are associated with poor neurological outcomes and increased mortality $4,5,6,7,8$ Cerebrovascular complications can occur at the onset of the infection, during hospitalization, or weeks after successful treatment. $4,7,9$

\section{Arterial infarction}

Arterial infarction (Figure 1) occurs in $8-25 \%$ of bacterial meningitis cases and accounts for $70-85 \%$ of all cerebrovascular events. ${ }^{4,5,6,7,10}$ Even though ischemic events tend to occur early in the course of disease (1-2 weeks), ischemic stroke or vasculopathy may develop months after successful treatment or recovery.9,11,12 In 1,032 meningitis episodes, delayed cerebral thrombosis defined as initial recovery with sudden deterioration after the first week of admission caused by cerebral infarction occurred in 11 patients $(1.1 \%) .{ }^{13}$ The outcome of patients with delayed cerebral thrombosis is very poor. ${ }^{13,14}$

A reduced level of consciousness at admission, the presence of seizures, low CSF white cell counts, and high ESR are predictors of infarction or cerebral arterial narrowing. ${ }^{5,7,15}$ The posterior circulation is less commonly affected than anterior circulation, and strokes in this region are better tolerated clinically than in the anterior circulation. ${ }^{16,17}$ The middle cerebral artery is the most commonly affected artery in bacterial men- 
ingitis-induced cerebral infarction. ${ }^{4}$

Cerebral angiography typically shows vascular changes in various segments of the arteries. Small vessel involvement may result in loss of arterial autoregulation demonstrated angiographically by focal abnormal parenchymal blush associated with hyperperfusion. ${ }^{6}$ In a series of 35 patients, transient intra- cranial stenosis of the middle and anterior cerebral arteries was detected by transcranial Doppler sonograms (TCD) in $50 \%$ of patients within day 3-5 of onset of the disease. ${ }^{17}$ Some studies have demonstrated an association between the arterial narrowing detected by the bedside TCD and increased risk of stroke. . $^{8,18}$
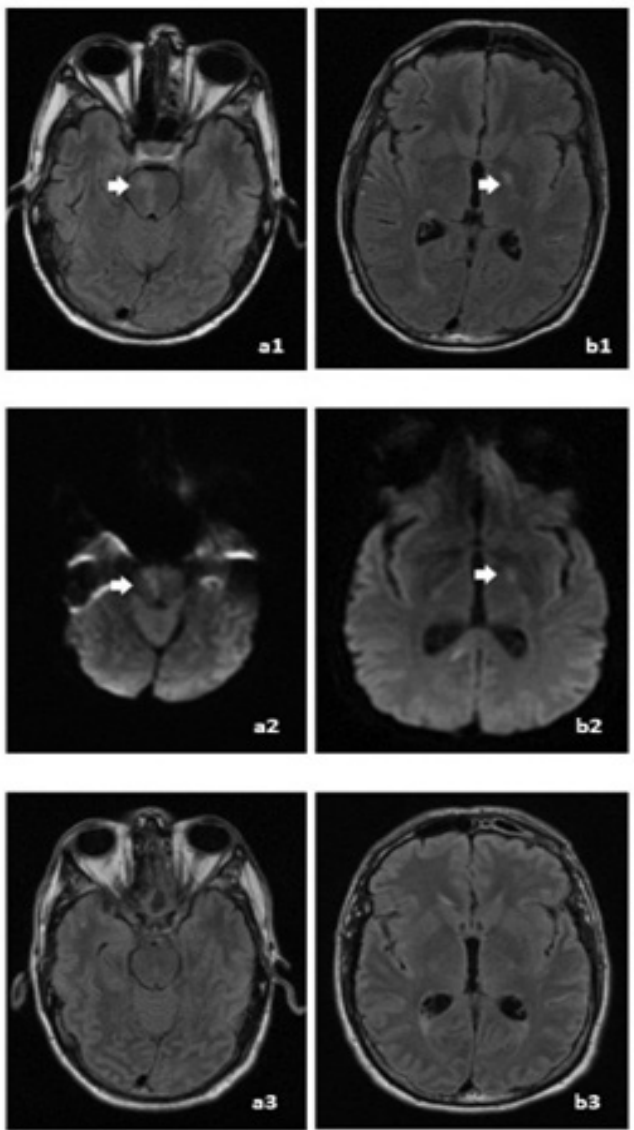
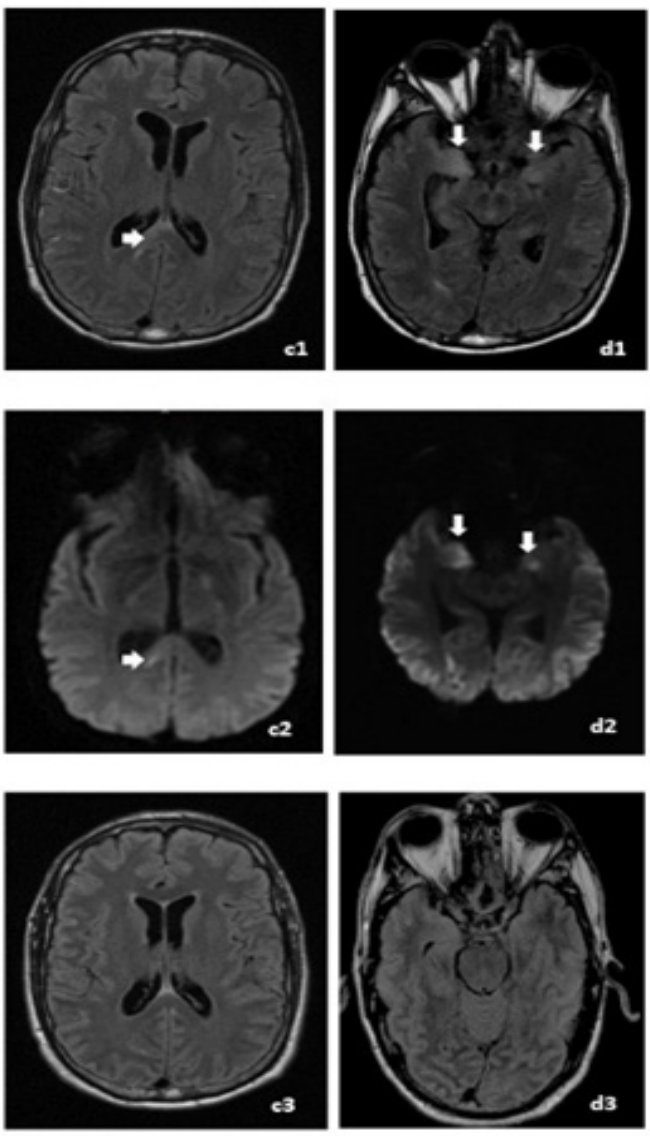

Figure 1. New infarction at the right medial pons (a1, a2), the left capsulothalamic area (b1, b2), the right-sided splenium of corpus callosum ( $\mathrm{c} 1$, c2) and the bilateral mesial temporal areas $(\mathrm{d} 1$, d2) shown by FLAIR (top row) and DWI (middle row) (day 30 after admission); The MRI on the day of admission showed no infarction at these areas $(\mathrm{a} 3, \mathrm{~b} 3, \mathrm{c} 3, \mathrm{~d} 3$; bottom row)

eventually cause vascular stenosis. ${ }^{19}$ The activation of coagulation and attenuation of fibrinolysis in the CSF may also contribute to the cerebral infarction. ${ }^{21}$ Post-infectious processes may trigger autoimmunity to the cerebral vessels and cause late onset vasculopathy.

The role of antithrombotic or thrombolysis in the treatment of arterial ischemia associated with bacterial meningitis is unclear. Delayed vasculopathy is rare, and there are no systematic studies on how to best 
treat this complication. Immunosuppressive therapy was reportedly beneficial in one case ${ }^{22}$ Clinical worsening has been reported during tapering corticosteroids in some cases. ${ }^{9,22}$

\section{Venous infarction}

Venous infarction involves thrombosis of either dural venous sinuses, deep veins, or cortical veins. ${ }^{8,12}$ The incidence of venous infarction is far less than arterial infarction. In 87 pneumococcal meningitis patients, venous infarction occurred in $10 \%$ of cases. ${ }^{12}$ The cortical vein was the most commonly affected vessel accounting for $46 \%$ of the venous infarctions followed by dural venous sinuses (36\%) and the deep cerebral venous system, including internal jugular veins $(18 \%){ }^{12}$

Due to the rarity of venous thrombosis in bacterial meningitis, prospective trials on the role of anticoagulants in this condition have not been performed.
Based on limited information, heparin should be started cautiously after the patient develops clinical symptoms associated with venous infarction

\section{Hemorrhagic stroke}

Intracranial hemorrhage $(\mathrm{ICH})$ is less common than ischemic stroke and occurs in 2-9 \% of all bacterial meningitis patients, approximately $14-28 \%$ of all stroke events. ${ }^{4,10,23}$ However, in a series of patients with $\mathrm{S}$. aureus meningitis, $\mathrm{ICH}$ developed in $38 \%$ of cases and was highly associated with infective endocarditis (IE). ${ }^{23}$ There are several types of $\mathrm{ICH}$ in bacterial meningitis, including intraparenchymal hemorrhage and microbleeds from arterial bleeding, hemorrhagic transformation of arterial or venous infarcts, subarachnoid hemorrhage (Figure 3), and abscess formation with subsequent hemorrhagic transformation. ${ }^{10,23,24}$ In $S$. aureus meningitis, hemorrhagic transformation after cerebral infarction by septic embolism may occur. ${ }^{23,25}$ Subarachnoid hemorrhage caused by

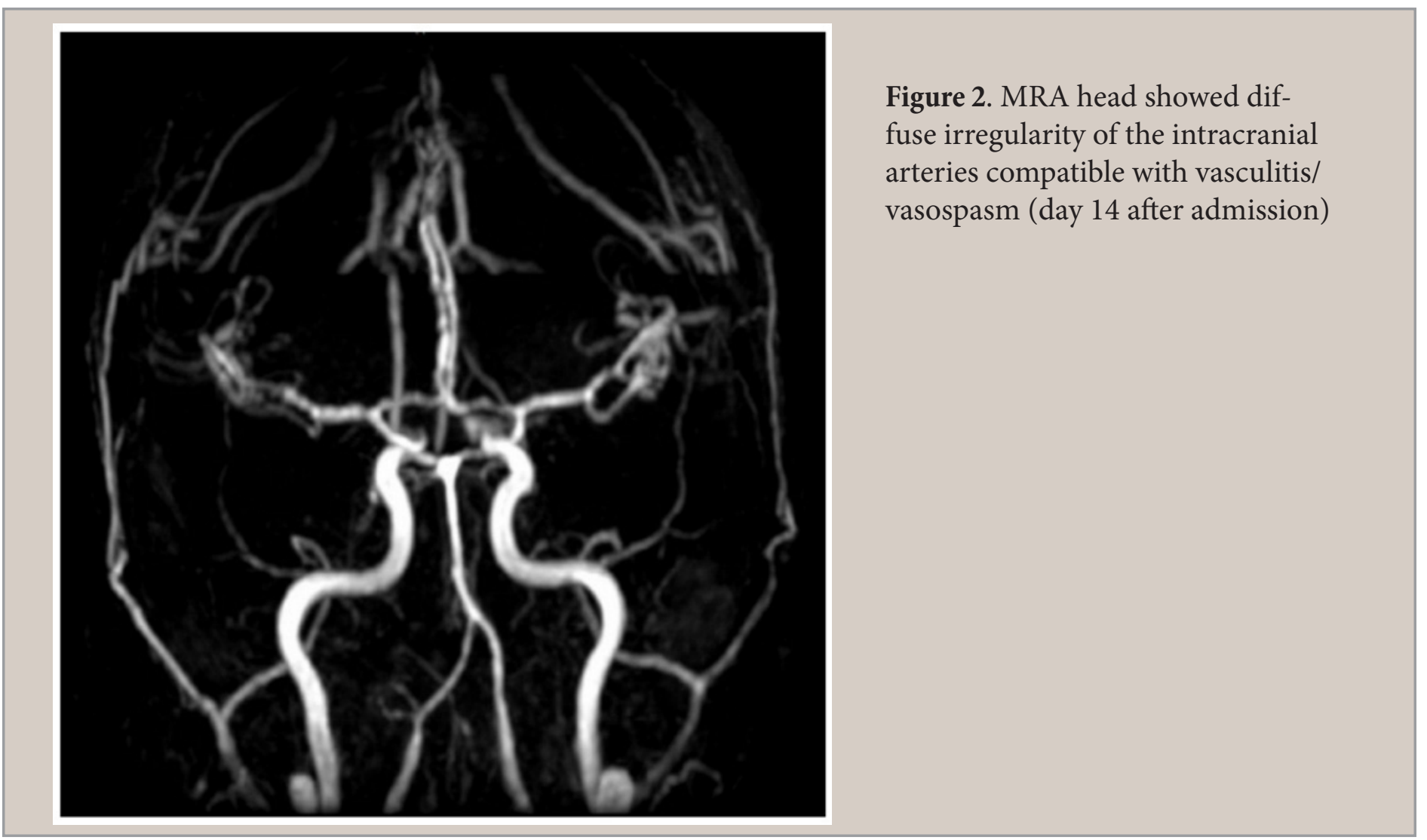


ruptured inflammatory arteritis or aneurysms is a rare complication of bacterial meningitis. ${ }^{10,23}$

\section{VESTIBULOCOCHLEAR NEUROPATHY}

The vestibulocochlear nerve is the cranial nerve most affected by bacterial meningitis. Hearing loss complicates $22-54 \%$ of adult patients with pneumococcal meningitis; $23-47 \%$ have moderate to severe hearing loss. ${ }^{10,26,27}$ In meningitis caused by Streptococcal suis, hearing loss occurs in half of patients. ${ }^{28}$ Hearing loss can also be caused by meningitis from Neisseria meningitides, Haemophilus influenza, Streptococcus equi, and Streptococcus bovis. ${ }^{29,30}$

Bacterial dissemination from the subarachnoid space to perilymphatic space of the cochlea leads to inflammation and damage of the blood-labyrinth barrier, ganglion, and hair cells which subsequently cause suppurative inflammation and ossification of cochlear and semicircular canals. ${ }^{31,32}$ Use of corticosteroids can reduce hearing loss in adults with suspected or proven community-acquired bacterial meningitis. ${ }^{33}$

After profound hearing loss is established, cochlear implantation can improve hearing thresholds. The timing of implantation after meningitis is controversial. Early implantation can avoid dealing with labyrinthitis ossificans (LO) and improves hearing performances. In cases managed conservatively, periodic MRI may detect early signs of LO, and that would be an indication for implantation. ${ }^{34,35}$

\section{Altered mental Status (AMS) AND IN- CREASED INTRACRANIAL PRESSURE (ICP)}

The spectrum of mental status changes seen in these cases ranges from irritability to coma. AMS occurs in approximately $80 \%$ of cases with bacterial meningitis. Increased ICP in bacterial meningitis is caused by several factors that raise intracerebral fluid volume, causing cerebral edema. These factors

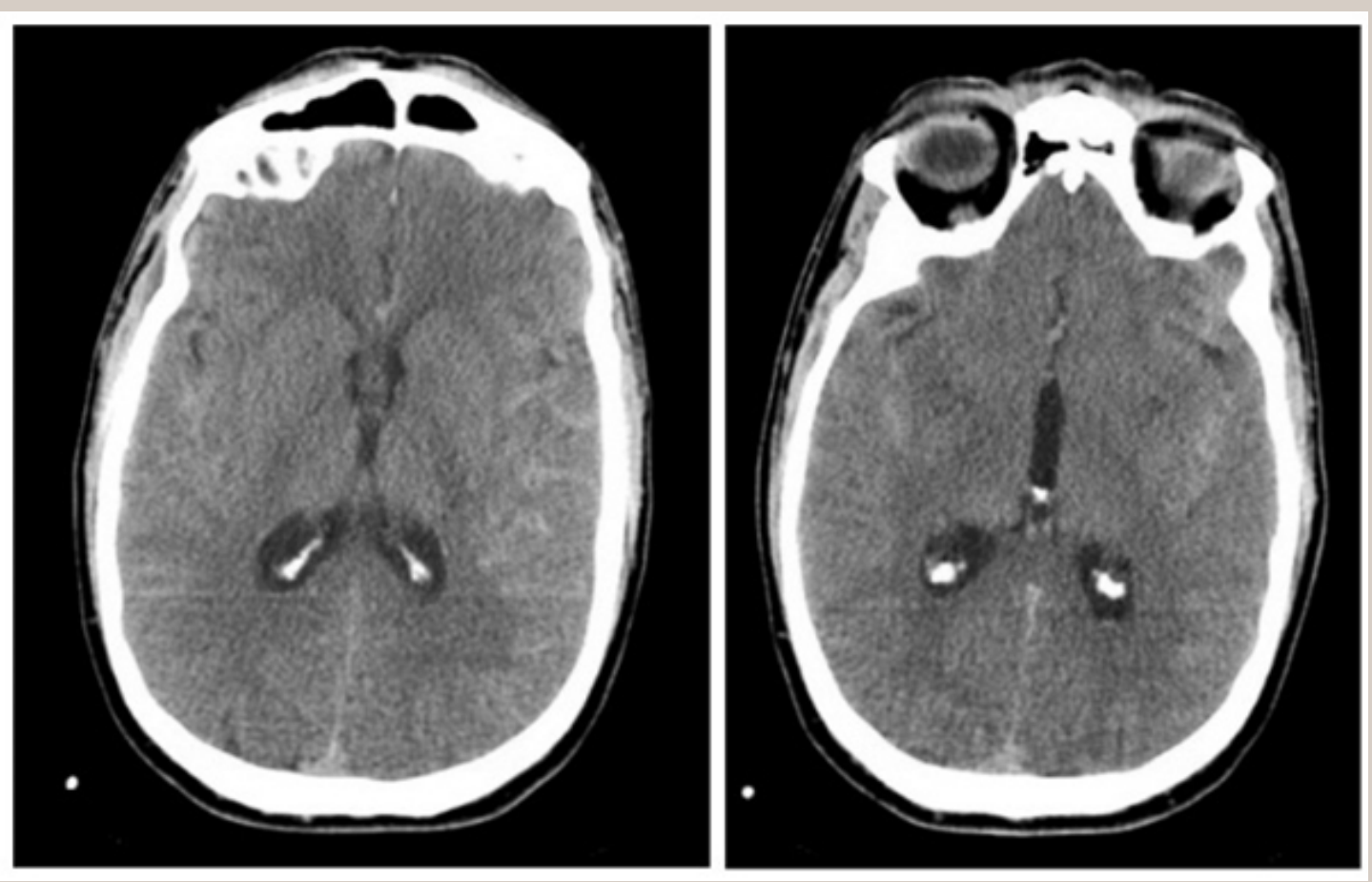

Figure 3. Diffuse subarachnoid hemorrhage in the bilateral posterior frontal temporal convexities extending minimally into the parietal lobes (on the day of admission) 
include cytotoxic factors released by bacteria and neutrophils, vasogenic edema from increased bloodbrain barrier permeability, and poor CSF reabsorption caused by arachnoiditis.

The management of increased ICP includes appropriate fluid management, osmotic therapy, hypertonic saline, hyperventilation with the $\mathrm{PaCO}_{2} 25-35 \mathrm{mmHg}$, head elevation, and CSF drainage. In a double-blind, randomized controlled trial, oral glycerol therapy used to decrease intracranial pressure increased mortality and neurological disability in adult patients with bacterial meningitis (83\%). ${ }^{36} \mathrm{~A}$ retrospective study suggested that lumbar drainage of CSF targeting ICP of $<10 \mathrm{mmHg}$ in severe bacterial meningitis was safe and contributed to lower mortality and morbidity. ${ }^{37}$ At this point, these various measures to decrease ICP are best used based on clinical indication rather than as a routine treatment.

\section{HYDROCEPHALUS}

Hydrocephalus occurs in $3-21 \%$ of patients. ${ }^{38,39,40}$ This condition is associated with higher mortality and poorer neurological outcomes. ${ }^{38,39}$ Because the infection affects primarily the meninges, communicating hydrocephalus due to blockade of CSF absorption by leptomeningeal inflammation is more common. Obstructive hydrocephalus due to aqueduct obstruction is less common and can result from infected debris or complicated intraventricular pus as found in this case (Figure 4). Mild to moderate hydrocephalus can be conservatively managed with close monitoring; severe hydrocephalus causing increased intracranial pressure must be treated with neurosurgical intervention.

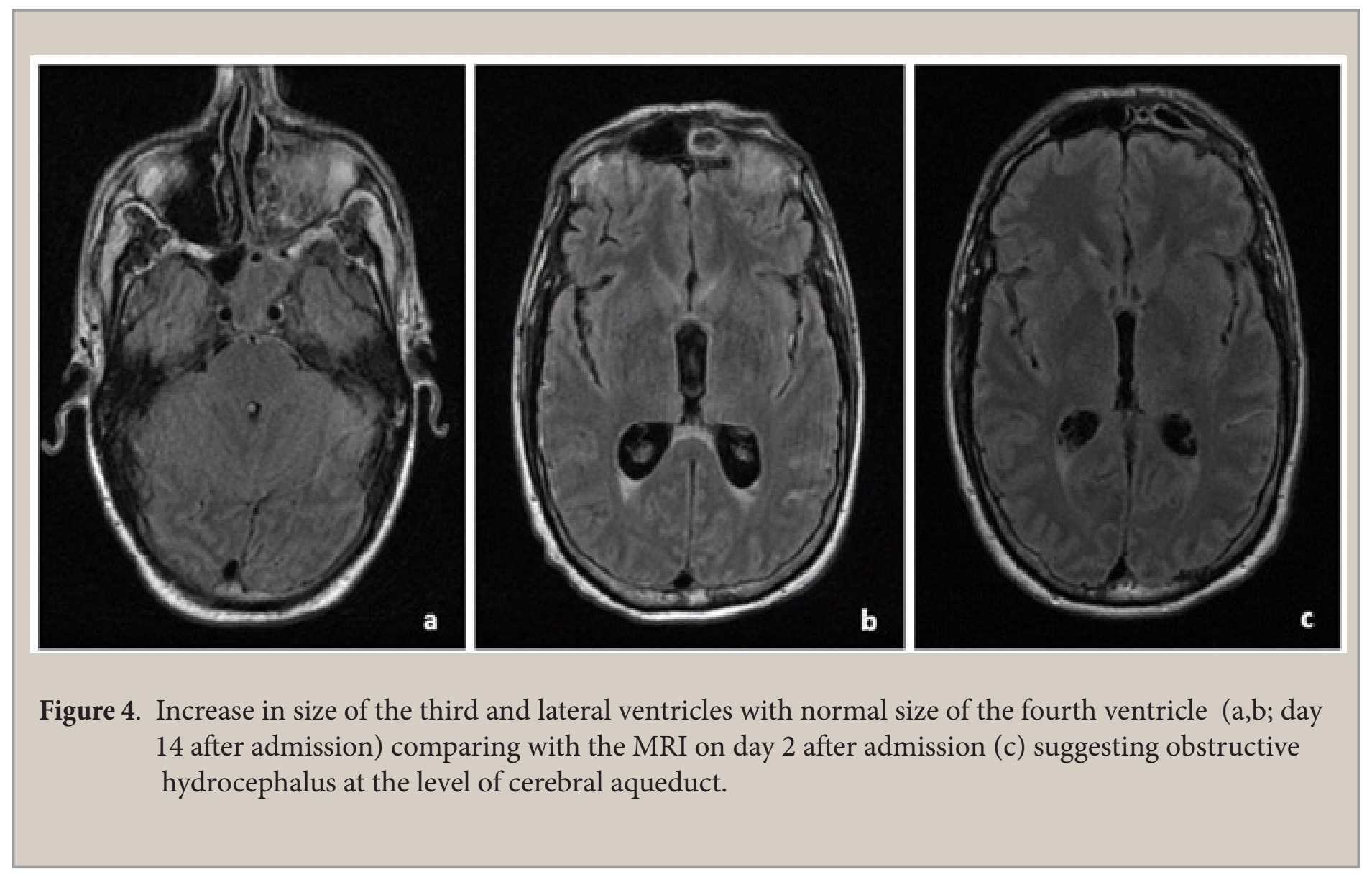




\section{SeIZURES}

Seizures can complicate bacterial meningitis as a result of the inflammatory exudate, bacterial toxins, and changes within the cortex. Seizures are reported in $15-30 \%$ of adult patients with bacterial meningitis. ${ }^{41}$ Seizures occurring in the acute phase of the bacterial meningitis in adults are a poor prognostic factor and suggest a more severe and diffuse spread of the infection to the brain parenchyma. ${ }^{41,42}$ These patients have a higher risk of recurrent seizures over the ensuing five years and have a higher risk of persistent neurologic deficits and death. ${ }^{41,43}$

\section{BRAIN ABSCESS AND FOCAL CEREBRITIS}

Brain abscess and focal cerebritis can be either the cause of or a complication of bacterial meningitis. Brain abscess is a more common complication of meningitis due to $S$. aureus and less often in meningitis from $S$. pneumoniae, $H$. influenzae, and $N$. meningitidis. ${ }^{23}$

Treatment requires broad spectrum antibiotics, such as third or fourth generation cephalosporins plus metronidazole, which also cover anaerobic bacteria, and neurosurgical consultation. If patients have a history of trauma or recent neurosurgical procedures, vancomycin should be added to an empirical regimen.

\section{SUBDURAL EFFUSION/ EMPYEMA}

Bacterial meningitis can result in collection of extra-axial fluid that may be sterile (subdural effusion) or infected (subdural empyema). Subdural empyema (Figure 5 ) is reported in $5 \%$ of patients with bacterial meningitis. ${ }^{44}$ Patients can present with fever, new onset of seizure, or increased ICP. Differentiating subdural empyema from effusion requires clinical features and neuroimaging. Most cases of subdural empyema are unilateral, but they have potential to spread rapidly through the dural folds to the base of the brain
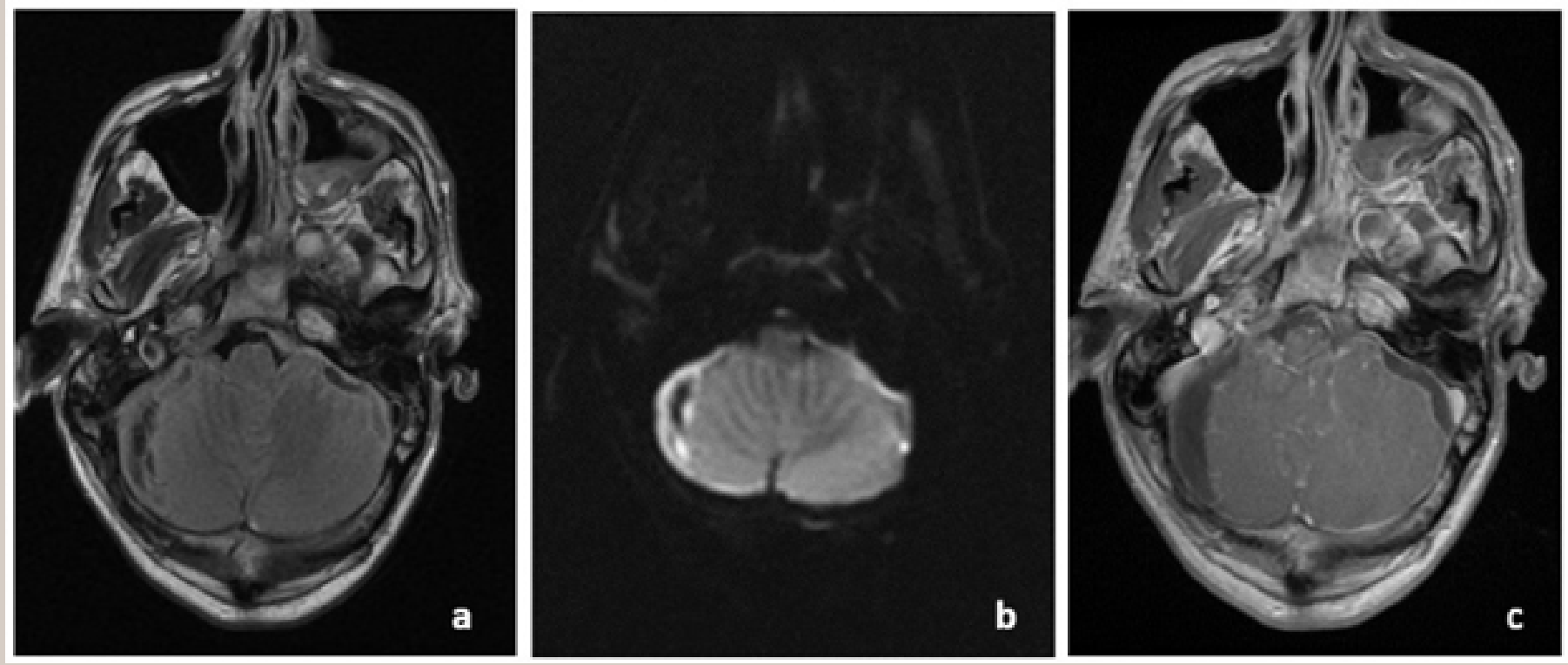

Figure 5. Subdural empyema at the posterior fossa on FLAIR (a), DWI (b) and T1 with gadolinium contrast (c) MRI (day 14 after admission) 

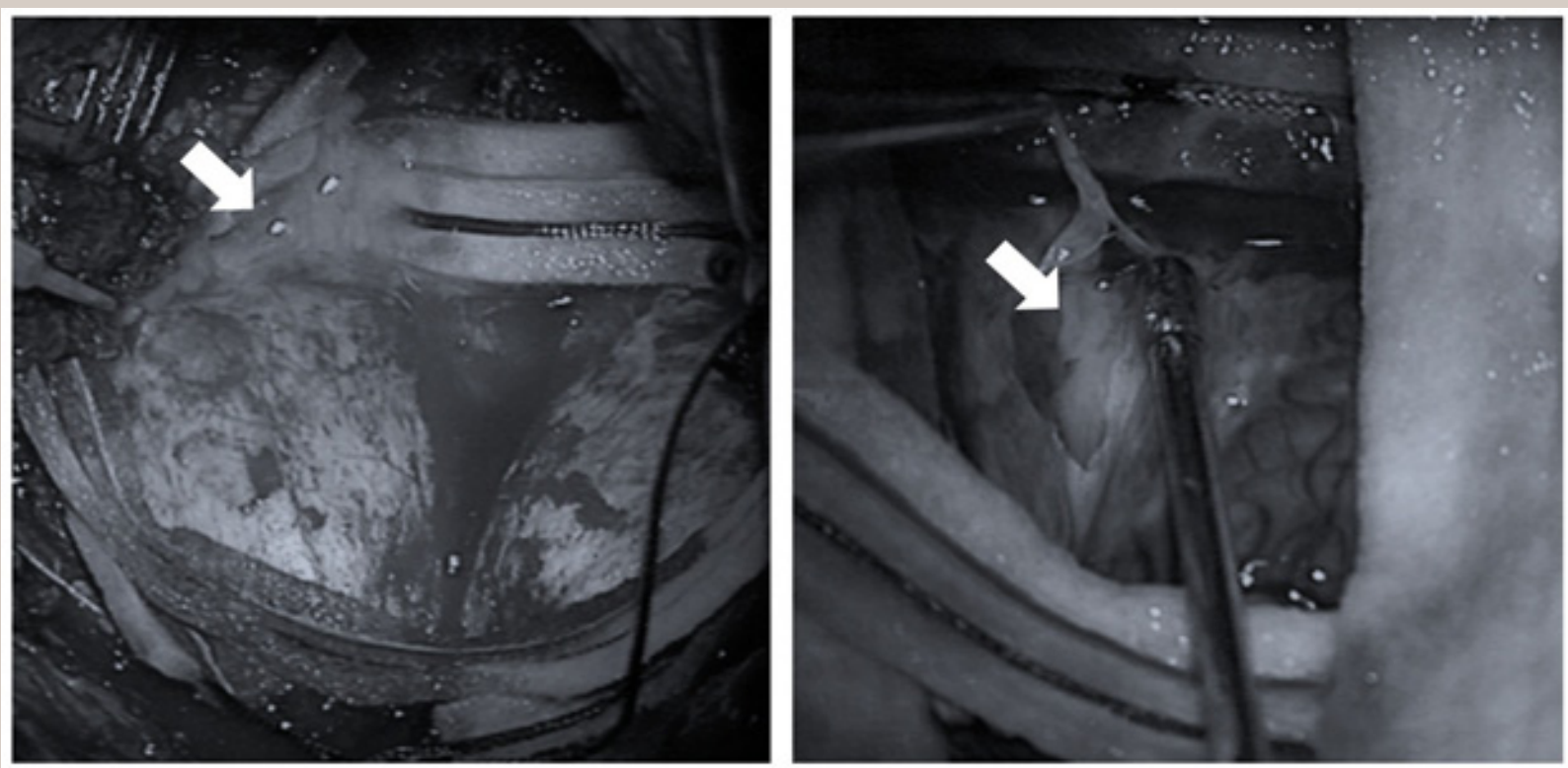

Figure 6. Posterior craniotomy for subdural empyema drainage and extraventricular drainage for hydrocephalus. Arrows indicate subdural pus.

and spinal canal. Small subdural effusions usually resolve spontaneously, while patients with subdural empyema tend to have persistent or recurrent fever or focal neurological deficits requiring surgical drainage (Figure 6).

\section{VENTRICULITIS AND PYOGENIC INTRAVENTRIC- ULAR EMPYEMA}

Ventriculitis and intraventricular empyema were not considered a common complication of bacterial meningitis. With the advent of routine MRI, it has become apparent that signs of pyogenic ventriculitis are not uncommon. In one retrospective series, this complication was seen in $54.7 \%$ of acute bacterial meningitis. ${ }^{44}$ Pyogenic intraventricular empyema shows restricted diffusion on the diffusion-weight imaging at the dependent parts of the ventricles (Figure 7). In ventriculitis, imaging may show irregular debris in ventricles, hydrocephalus, and ependymal contrast enhancement. ${ }^{44,45}$ The role of intrathecal and intraventricular antibiotic is not well studied in bacterial men- ingitis in non-neurosurgical cases. Systemic antibiotic therapy is usually sufficient to treat the ventriculitis. ${ }^{46}$

\section{HYPOTHALAMIC AND OTHER ENDOCRINE DYS- FUNCTION}

Hypothalamic-pituitary dysfunction is not a common complication of bacterial CNS infection. An analysis of the pituitary function of 19 patients with previous CNS infections, including meningitis, 10 to 56 months after acute infection, showed that $21 \%$ had isolated corticotropic insufficiency, and $11 \%$ had borderline gonadotropic insufficiency. No patient had somatotropic or thyrotropic insufficiency, evidence of diabetes insipidus, or abnormal prolactin concentrations. ${ }^{47}$ These cases suggest that screening for pituitary insufficiency may be justified in some patients with bacterial meningitis. ${ }^{48}$ Diabetes insipidus is seen in bacterial meningitis caused by $S$. pneumoniae and N. meningitides. ${ }^{49,50}$ 

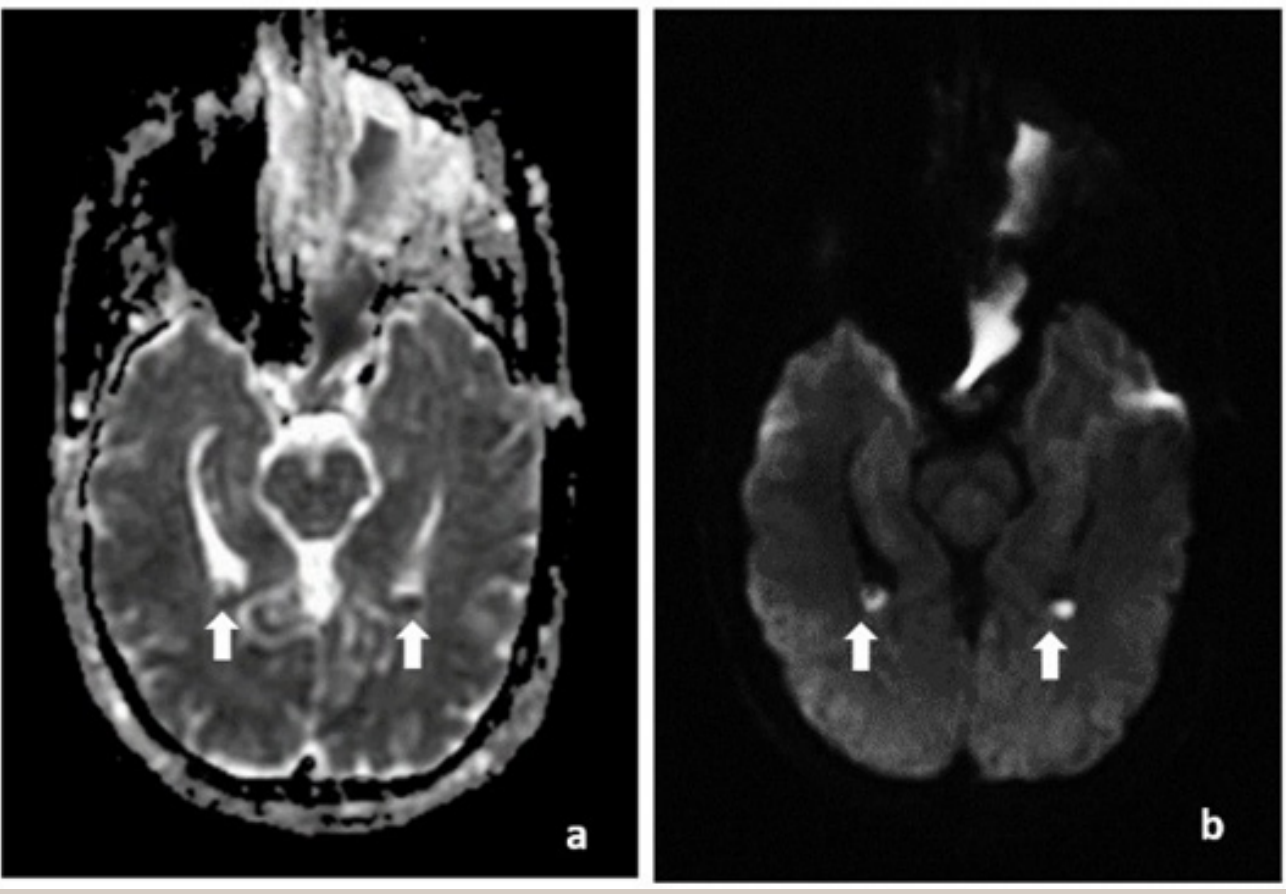

Figure 7.

Intraventricular material in the occipital horn of lateral ventricles with hypointensity in ADC (a) and restricted diffusion in DWI (b) MRI suspecting intraventricular empyema (day 14 after admission)

\section{Myelopathy AND RADICULOPATHY}

Myelopathy is also a rare complication of bacterial meningitis. The majority of the cases occur in children, and the presenting symptoms are quadriparesis, paraplegia, bowel and bladder dysfunction, and a sensory level loss. ${ }^{51}$ In cases with cervicomedullary involvement, respiratory arrest can happen abruptly or following lumbar puncture. Subarachnoid infection can cause vasculitis or vasospasm of the arteries of the spinal cord resulting in spinal cord infarction. Brain edema with herniation can cause compressive vasculopathy by compressing the spinal artery around the foramen magnum and cause infarction of the craniocervical cord. Hypotension during the septic shock can also contribute to spinal vasculopathy.

Compressive myelopathy directly causes spinal cord damage. Tonsillar herniation secondary to increased ICP may compress the brainstem at the cervicomedullary junction resulting in compressive myelopathy. ${ }^{52,53}$ Spinal epidural abscess is a rare complication of bacterial meningitis that can com- press the spinal cord. The diagnosis of epidural abscess requires radiological confirmation with MRI with gadolinium or CT myelogram. Early detection and drainage can prevent permanent damage. ${ }^{54}$

Myelitis is another serious form of myelopathy caused by bacterial meningitis. Meningococcal, Neisserial and Streptococcal meningitis have been reported to cause myelitis in adults. ${ }^{55,56}$ Inflammation in the subarachnoid space can spread from the intracranial space to the spinal canal and cause polyradiculitis. Patients can have asymmetrically flaccid weakness of proximal and distal muscle groups of the extremities with alteration of sensation and decreased deep tendon reflexes.

\section{Cognitive AND NEUROPSYCHIATRIC OUT- COMES}

Cognitive and neuropsychiatric impairments following bacterial meningitis can be the result of direct damage to cerebral structures by the infection 
or can be secondary to complications from the infection. The degree of cognitive impairment ranges from relatively mild to severe and occurs in up to $32 \%$ of surviving adults. ${ }^{57}$ Functions that are more commonly affected included psychomotor and cognitive processing, visuospatial skills, concentration, and memory. Treatment with dexamethasone during the acute infection did not seem to help long term cognitive function after bacterial meningitis. ${ }^{57,58}$ Other common and often very incapacitating long term consequences of bacterial meningitis are depression and reduced quality of sleep..$^{59,60,61}$

\section{Conclusions}

Bacterial meningitis is a central nervous system infection which causes high mortality rates in adults. The direct infection at the leptomeninges can cause indirect complications to other nervous system structures, such as cerebral and spinal vessels, ventricles, cranial nerves, brain parenchyma, spinal cord, spinal nerve roots, hypothalamus, and pituitary. The onset of these complications can occur from disease presentation to several months after the treatment. Awareness of these complications should lead to the early detection and appropriate treatment which can improve the recovery outcomes.

Author Affiliations: Parunyou Julayanont and Doungporn Ruthirago are residents in the Department of Neurology at Texas Tech University Health Sciences Center in Lubbock, TX. John C. DeToledo is the chairman of Neurology at TTUHSC in Lubbock.

Submitted: 3/10/2016

Accepted: 4/7/2016

Reviewers: Richard Winn MD

Published electronically: 4/15/2016

Conflict of Interest Disclosures: None

\section{REFERENCES}

1. Van de Beek D, de Gans J, Spanjaard L, Weisfelt M, Reitsma JB, Vermeulen M. Clinical features and prognostic factors in adults with bacterial meningitis. N Engl J Med 2004; 351(18):1849-59.

2. Flores-Cordero JM, Amaya-Villar R, Rincón-Ferrari MD, Leal-Noval SR, Garnacho-Montero J, Llanos-Rodríguez $\mathrm{AC}$, et al. Acute community-acquired bacterial meningitis in adults admitted to the intensive care unit: clinical manifestations, management and prognostic factors. Intensive Care Med 2003; 29(11):1967-73.

3. Thigpen MC, Whitney CG, Messonnier NE, Zell ER, Lynfield R, Hadler JL, et al. Bacterial meningitis in the United States, 1998-2007. N Engl J Med 2011; 364(21):2016-25.

4. Bodilsen J, Dalager-Pedersen M, Schønheyder HC, Nielsen H. Stroke in community-acquired bacterial meningitis: a Danish population-based study. Int J Infect Dis 2014; 20:18-22.

5. Schut ES, Lucas MJ, Brouwer MC, Vergouwen MDI, van der Ende A, van de Beek D. Cerebral infarction in adults with bacterial meningitis. Neurocrit Care 2012; 16(3):421-7.

6. Pfister HW, Borasio GD, Dirnagl U. Cerebrovascular complications of bacterial meningitis in adults. Neurology 1992; 42(8):1497-504.

7. Katchanov J, Heuschmann PU, Endres M, Weber JR. Cerebral infarction in bacterial meningitis: predictive factors and outcome. J Neurol 2010; 257(5):716-20.

8. Müller M, Merkelbach S, Hermes M, König J, Schimrigk K. Relationship between short-term outcome and occurrence of cerebral artery stenosis in survivors of bacterial meningitis. J Neurol 1998; 245(2):87-92.

9. Kato Y, Takeda H, Dembo T, Tanahashi N. Delayed recurrent ischemic stroke after initial good recovery from pneumococcal meningitis. Intern Med 2012; 51(6):647-50.

10. Kastenbauer S, Pfister H-W. Pneumococcal meningitis in adults: Spectrum of complications and prognostic factors in a series of 87 cases. Brain 2003; 126(5):1015-25.

11. Palacio S, Hart R. Late-developing cerebral arteropathy after pyogenic meningitis. Arch Neurol 2003; 60(3):431-3.

12. Kawaguchi T, Ogawa Y. Cerebral arteritis with extremely late onset secondary to bacterial meningitis-case report. Neurol Med Chir (Tokyo) 2011; 51(4):302-5.

13. Lucas MJ, Brouwer MC, van de Beek D. Delayed cerebral thrombosis in bacterial meningitis: a prospective cohort study. Intensive Care Med 2013; 39(5):866-71.

14. Schut ES, Brouwer MC, de Gans J, Florquin S, Troost D, van de Beek D. Delayed cerebral thrombosis after initial good recovery from pneumococcal meningitis. Neurology 2009; 73(23):1988-95.

15. Merkelbach S, König J, Röhn S, Müller M. The use of 
clinical scales in depicting cerebrovascular complications in bacterial meningitis. J neuroimaging 2001; 11(1):25-9.

16. Müller M, Merkelbach S, Schimrigk K. Cerebral hemodynamics in the posterior circulation of patients with bacterial meningitis. Acta Neurol Scand 1996; 93(6):443-9.

17. Müller M, Merkelbach S, Huss GP, Schimrigk K. Clinical relevance and frequency of transient stenoses of the middle and anterior cerebral arteries in bacterial meningitis. Stroke 1995; 26(8):1399-403.

18. Klein M, Koedel U, Pfefferkorn T, Zeller G, Woehrl B, Pfister H-W. Arterial cerebrovascular complications in 94 adults with acute bacterial meningitis. Crit care 2011; 15(6):R281.

19. Yamashima T, Kashihara K, Ikeda K, Kubota T, Yamamoto $\mathrm{S}$. Three phases of cerebral arteriopathy in meningitis: vasospasm and vasodilatation followed by organic stenosis. Neurosurgery $1985 ; 16(4): 546-53$.

20. Vergouwen MDI, Schut ES, Troost D, van de Beek D. Diffuse cerebral intravascular coagulation and cerebral infarction in pneumococcal meningitis. Neurocrit Care 2010; 13(2):21727.

21. Weisfelt M, Determann RM, de Gans J, van der Ende A, Levi M, van de Beek D, et al. Procoagulant and fibrinolytic activity in cerebrospinal fluid from adults with bacterial meningitis. $\mathrm{J}$ Infect 2007; 54(6):545-50.

22. Pugin D, Copin JC, Goodyear MC, Landis T, Gasche Y. Persisting vasculitis after pneumococcal meningitis. Neurocrit Care 2006; 4(3):237-40.

23. Mook-Kanamori BB, Fritz D, Brouwer MC, van der Ende A, van de Beek D. Intracerebral hemorrhages in adults with community associated bacterial meningitis in adults: should we reconsider anticoagulant therapy? PLoS One 2012; 7(9):e45271.

24. Sakai K, Ono K, Ohta K, Yamada M. Progression of cerebrovascular lesions in pneumococcal meningitis. Intern Med 2010; 49(12):1261-2.

25. Rasmussen R V, Snygg-Martin U, Olaison L, Buchholtz K, Larsen CT, Hassager C, et al. Major cerebral events in Staphylococcus aureus infective endocarditis: is anticoagulant therapy safe? Cardiology 2009; 114(4):284-91.

26. Heckenberg SGB, Brouwer MC, van der Ende A, Hensen EF, van de Beek D. Hearing loss in adults surviving pneumococcal meningitis is associated with otitis and pneumococcal serotype. Clin Microbiol Infect 2012; 18(9):849-55.

27. Worsøe L, Cayé-Thomasen P, Brandt CT, Thomsen J, Østergaard C. Factors associated with the occurrence of hearing loss after pneumococcal meningitis. Clin Infect Dis 2010; 51(8):917-24.

28. Huong VTL, Ha N, Huy NT, Horby P, Nghia HDT, Thiem VD, et al. Epidemiology, clinical manifestations, and outcomes of Streptococcus suis infection in humans. Emerg Infect Dis 2014; 20(7):1105-14.
29. Sandyk R, Brennan M. Meningococcal meningitis presenting with bilateral deafness and ataxia. Postgrad Med J. 1984; 60(708):668-9.

30. Eyre DW, Kenkre JS, Bowler ICJW, McBride SJ. Streptococcus equi subspecies zooepidemicus meningitis--a case report and review of the literature. Eur J Clin Microbiol Infect Dis 2010; 29(12):1459-63.

31. Nadol JB, Hsu WC. Histopathologic correlation of spiral ganglion cell count and new bone formation in the cochlea following meningogenic labyrinthitis and deafness. Ann Otol Rhinol Laryngol 1991; 100(9 Pt 1):712-6.

32. Caye-Thomasen P, Dam MS, Omland SH, Mantoni M. Cochlear ossification in patients with profound hearing loss following bacterial meningitis. Acta Otolaryngol 2012; 132(7):7205.

33. Brouwer MC, McIntyre P, Prasad K, van de Beek D. Corticosteroids for acute bacterial meningitis. Cochrane database Syst Rev 2013; 6:CD004405.

34. Philippon D, Bergeron F, Ferron P, Bussières R. Cochlear implantation in postmeningitic deafness. Otol Neurotol 2010; 31(1):83-7.

35. van Loon MC, Hensen EF, de Foer B, Smit CF, Witte $\mathrm{B}$, Merkus P. Magnetic resonance imaging in the evaluation of patients with sensorineural hearing loss caused by meningitis: implications for cochlear implantation. Otol Neurotol 2013; 34(5):845-54.

36. Ajdukiewicz KM, Cartwright KE, Scarborough M, Mwambene JB, Goodson P, Molyneux ME, et al. Glycerol adjuvant therapy in adults with bacterial meningitis in a high HIV seroprevalence setting in Malawi: a double-blind, randomized controlled trial. Lancet Infect Dis 2011; 11(4):293-300.

37. Abulhasan YB, Al-Jehani H, Valiquette M-A, McManus A, Dolan-Cake M, Ayoub O, et al. Lumbar drainage for the treatment of severe bacterial meningitis. Neurocrit Care 2013; 19(2):199-205.

38. Kasanmoentalib ES, Brouwer MC, van der Ende A, van de Beek D. Hydrocephalus in adults with community-acquired bacterial meningitis. Neurology 2010; 75(10):918-23.

39. Bodilsen J, Schønheyder HC, Nielsen H. Hydrocephalus is a rare outcome in community-acquired bacterial meningitis in adults: a retrospective analysis. BMC Infect Dis 2013; 13:321. 40. Wang K-W, Chang W-N, Chang H-W, Wang H-C, Lu $\mathrm{C}-\mathrm{H}$. Clinical relevance of hydrocephalus in bacterial meningitis in adults. Surg Neurol 2005; 64(1):61-5; discussion 66.

41. Zoons E, Weisfelt M, de Gans J, Spanjaard L, Koelman JHTM, Reitsma JB, et al. Seizures in adults with bacterial meningitis. Neurology 2008; 70 (22 Pt 2):2109-15.

42. Aronin SI, Peduzzi P, Quagliarello VJ. Community-acquired bacterial meningitis: Risk stratification for adverse clinical outcome and effect of antibiotic timing. Ann Intern Med 
1998; 129(11):862-9.

43. Annegers JF, Hauser WA, Beghi E, Nicolosi A, Kurland LT. The risk of unprovoked seizures after encephalitis and meningitis. Neurology 1988; 38(9):1407-10.

44. Lummel N, Koch M, Klein M, Pfister HW, Brückmann H, Linn J. Spectrum and Prevalence of Pathological Intracranial Magnetic Resonance Imaging Findings in Acute Bacterial Meningitis. Clin Neuroradiol 2014. (Online publication September 23, 2014)

45. Fukui MB, Williams RL, Mudigonda S. CT and MR imaging features of pyogenic ventriculitis. Am J Neuroradiol 2001; 22(8):1510-6.

46. Woehrl B, Linn J, Lummel N, Pfefferkorn T, Koedel U, Pfister H-W, et al. Pneumococcal meningitis-associated pyogenic ventriculitis. J Infect 2015; 70(3):311-4.

47. Schaefer S, Boegershausen N, Meyer S, Ivan D, Schepelmann K, Kann PH. Hypothalamic-pituitary insufficiency following infectious diseases of the central nervous system. Eur J Endocrinol 2008; 158(1):3-9.

48. Tsiakalos A, Xynos ID, Sipsas N V, Kaltsas G. Pituitary insufficiency after infectious meningitis: a prospective study. J Clin Endocrinol Metab 2010; 95(7):3277-81.

49. Franco-Paredes C, Evans J, Jurado R. Diabetes insipidus due to Streptococcus pneumoniae meningitis. Arch Intern Med 2001; 161(8):1114-5.

50. Christensen C, Bank A. Meningococcal meningitis and diabetes insipidus. Scand J Infect Dis 1988; 20(3):341-3.

51. Moffett KS, Berkowitz FE. Quadriplegia complicating Escherichia coli meningitis in a newborn infant : case report and review of 22 cases of spinal cord dysfunction in patients with acute bacterial meningitis. Clin Infect Dis 1997; 25(2):211-4.

52. Ropper AH, Kanis KB. Flaccid quadriplegia from tonsillar herniation in pneumococcal meningitis. J Clin Neurosci 2000; 7(4):339-41.

53. Muralidharan R. Cervicomedullary injury after pneumococcal meningitis with brain edema. Arch Neurol 2011; 68(4):513-6.

54. Talwalkar N, Debnath U, Medhian S. Quadriparesis from a panspinal extradural abscess following pneumococcal meningitis. Acta Orthop Belg 2006; 72(5):647-50.

55. Kastenbauer S, Winkler F, Fesl G, Schiel X, Ostermann $\mathrm{H}$, Yousry TA, et al. Acute severe spinal cord dysfunction in bacterial meningitis in adults. Arch Neurol 2001; 58(5):806-10.

56. Rathore MF, Gill ZA, Malik AA, Farooq F. Acute flaccid paraplegia: a rare complication of meningococcal meningitis. Spinal Cord 2008; 46(4):314-6.

57. Hoogman M, van de Beek D, Weisfelt M, de Gans J, Schmand B. Cognitive outcome in adults after bacterial meningitis. J Neurol Neurosurg Psychiatry 2007; 78(10):1092-6.

58. Weisfelt M, van de Beek D, Hoogman M, Hardeman C, de Gans J, Schmand B. Cognitive outcome in adults with moderate disability after pneumococcal meningitis. J Infect 2006; 52(6):433-9.

59. van de Beek D, Schmand B, de Gans J, Weisfelt M, Vaessen H, Dankert J, et al. Cognitive impairment in adults with good recovery after bacterial meningitis. J Infect Dis 2002; 186(7):1047-52.

60. Merkelbach S, Sittinger H, Schweizer I, Muller M. Cognitive outcome after bacterial meningitis. Acta Neurol Scand 2000; 102(2):118-23.

61. Schmidt H, Cohrs S, Heinemann T, Goerdt C, Djukic M, Heimann B, et al. Sleep disorders are long-term sequelae of both bacterial and viral meningitis. J Neurol Neurosurg Psychiatry $2006 ; 77(4): 554-8$. 